\title{
HUSSERL Y SARTRE FRENTE AL PROBLEMA DEL CONOCIMIENTO
}

1. Frente al acto de conocer, la actitud ingenua y espontánea es la de considerar que, fuera de mí, como sujeto cognoscente, hay cosas, y que estas cosas son tales como las conozco. Esta posición el realismo la adopta y hace de ella ipso facto una actitud filosófica valiosa: hay un pensamiento por una parte, $y$ un objeto por otra, los cuales existen separadamente, pero pueden comunicarse, puesto que sus estructuras concuerdan. Fundamentados en el ser, sujeto y objeto se encuentran en él. Es una evidencia del sentido común. El pensamientc extrae de su objeto lo inteligible que este objeto contiene; tiene, en efecto, el pensamiento, el poder de despojar a su objeto de lo que cambia, aparece y desaparece (accidentes), para lograr la realidad en sí, inmutable e inteligible, substrato de los accidentes (la substancia).

Juzgando que la evidencia del sentido común en la que se apoya el realismo dista de ser apodíctica, Descartes, en búsqueda de una primera certidumbre de la que pueda deducir todas las demás, no encuentra sino la de su propia existencia. "Cogito, ergo sum." El pensamiento quedó solo; él es el único absolutamente evidente; para él, hay la existencia de lo otro; en él residen los criterios de la verdad: la claridad y la distinción de las ideas. Desde luego, la existencia del mundo exterior está amenazada. dA título de qué existe todavía una realidad, si su estructura, su "verdad", no se hallan evidentemente sino en la conciencia? Será preciso que Dios, por su veracidad, garantice que un mundo exterior corresponde realmente a la impresión espontánea que tenemos de que tal mundo existe.

¿Este mundo, esta materia a distancia de mí, es conocida?, preguntará Berkeley. Si es conocida, es entonces de orden ideal, y no existe como materia en sí. Si no es conocida, ¿cómo, entonces, poder afirmar su existencia? Si no es percibida, ¿cómo puedo afirmarla? Y si es percibida, no tiene otro ser que el mismo de ser percibida. "Ens est percipi aut percipere." Tal es el idealismo en su forma más radical.

Aunque, en su punto de partida, Kant quiera establecer como dato primordial la experiencia, es decir, la intuición de un dato exterior, no escapa, finalmente, al idealismo: las formas mismas de mi conocimiento sensible -espacio y tiempo- son estructuras del sujeto. En estas formas se presenta "algo"; no se sabe qué, puesto que este "algo" no se nos puede aparecer sino a través y por medio de los cuadros intrasubjetivos. Entonces, ¿por qué guardar ese "algo" que cae bajo los golpes de la argumentación de Berkeley contra la materia? Si no es conocido, da nombre de qué afirmar su existencia? 
La última actitud que nos queda por considerar concede al idealismo que no hay que defender la existencia de una realidad más allá de las apariencias: substrato, substancia, manera de "núcleo" del mundo de los fenómenos. Esta substancia de Aristóteles, que vuelve a tomar por su cuenta Descartes, de la cual Kant mismo no supo totalmente deshacerse (el nóumeno, aunque incognoscible, existe por lo menos como límite de nuestro conocimiento), es una noción sin objeto, que ha estorbado a la filosofía hasta hoy en día, cargándola de "dualismos" insolubles. No hay otra realidad que la del fenómeno. Ningún ser en sí, "detrás de" la apariencia -estamos aquí muy cerca del idealismo-, pero hay el ser mismo de la apariencia, que no se reduce al ser de la conciencia -nos alejamos de Berkeley-. Esta última actitud, de un realismo de la apariencia o de un idealismo trascendental (lo que es equivalente), es la de la Fenomenología que, inaugurada por Edmundo Husserl, se mantiene como la estructura de base de la filosofía contemporánea hasta Jean Paul Sartre. Parece como si Husserl no hubiera visto todas las implicaciones de su genial descubrimiento. La existencia de la exterioridad del mundo, notablemente, no parece muy sólidamente establecida. Haremos entonces un llamado a Sartre, cuya argumentación contra el idealismo berkeliano es mucho más vigorosa, sin salirse, sin embargo, de la orientación filosófica fundamental de Husserl. Es evidente que no consideraremos a Husserl y a Sartre sino desde el punto de vista único del problema crítico del conocimiento que actualmente nos ocupa.

Examinaremos primero la fenomenología como método. Luego expondremos el cogito tal como lo concibe Husserl. Finalmente, veremos con Husserl y Sartre en qué sentido se debe entender la existencia de un mundo exterior.

2. Método fenomenológico. Cuando Husserl, al principio de nuestro siglo, va a desempeñar un papel en el desarrollo de la conciencia filosófica, dotándola en cierta forma de una nueva dimensión -la fenomenología-, el sistema en boga es el positivismo. Según la doctrina de Augusto Comte, las pretensiones de la filosofía son vanas. Alejémonos de esta infructuosa búsqueda de imposibles soluciones a problemas de otra edad. Contentémonos con tomar frente al mundo una actitud científica: registremos y ordenemos los hechos positivos, sin buscar lo que la experiencia no proporciona.

Frente a este positivismo, Husserl toma una actitud comparable a la de Kant para con el empirismo de Hume: puede ser legítimo no querer ocuparse sino de ciencia; pero esto no significa que la ciencia no necesite ser fundamentada. No es, en sí misma, su propio fundamento. La ley científica expresa una necesidad, a la que no justifica el solo hecho observable por la sola razón de que los hechos son siempre contingentes: no implican en sí mismos nada, sino su sola existencia. La ley de la física matemática no nos enseña que tal hecho siguió a otro, sino que a tal hecho, siendo tal, otro hecho seguirá necesariamente. Este vínculo necesario no está en el hecho observado. ¿En dónde 
está, pues? En otros términos, ¿qué es lo que fundamenta esta necesidad? ¿Qué es lo que fundamenta la ciencia?

La justificación de esta necesidad el realismo la creía hallar en una estructura metafísica de la realidad: la substancia. Si la ley física enuncia una relación necesaria y permanente es porque los hechos observados y cambiantes son apariencias de una realidad inmóvil. Lo que establece un vínculo permanente entre hechos transitorios es la substancia, para la cual estos hechos son accidentes que no tienen ningún ser, sino como apariencias de esta substancia que existe sola en sí, más allá de sus manifestaciones.

Desde Kant; al contrario, lo que garantiza esta necesidad del juicio científico no es una estructura metafísica de la realidad, un "núcleo" que constituiría el ser-en-sí, en relación con el fenómeno. Esta necesidad "no viene" de la experiencia, deducida de intuiciones que son siempre particulares y contingentes. Es, al contrario, la experiencia la que "viene de" ella; o, en otras palabras, esta necesidad constituye la condición a priori de la experiencia. Esta necesidad reside en las estructuras lógicas del entendimiento.

En esto Husserl se muestra de acuerdo con Kant. Pero esta explicación no le parece suficiente. No se ha llegado así a la fundamentación última. De acuerdo con el positivismo, Husserl exige una justificación de la lógica misma. Pero el desacuerdo no tarda en afirmarse entre el positivismo y Husserl, cuando se trata de saber en qué ha de fundamentarse esta lógica.

Es costumbre considerar a la lógica como una ciencia normativa; como tal, exige un fundamento teorético. Bajo pena de ser gratuita y absurda, una norma debe descansar sobre un hecho (la moral, como conjunto de las normas que deben seguir los hombres, tiene que apoyarse sobre lo que es el hombre, si no quiere correr el riesgo de ser gratuita e inaplicable).

Este fundamento teorético que exige la lógica es, para el positivismo, la psicología: sólo el estudio experimental de las estructuras del espíritu permitirá decidir después sobre la utilización que el espíritu deba hacer de aquellas estructuras.

Kant ya había refutado implícitamente esta pretensión psicologista, por el hecho mismo de que rehusaba el empirismo de Hume: la necesidad que se manifiesta en la ciencia normativa debe ser discernible igualmente en la ciencia teorética que la fundamenta. Ahora bien, la psicología, en tanto que experiencia de los hechos psíquicos, no presenta tal necesidad. Al contrario, usa, en tanto que estudio científico de los hechos de conciencia, una armadura lógica que desde luego presupone, en lugar de fundar. Para Kant, lo que fundamenta la lógica, como regla de aplicación del espíritu a un dato, es la lógica a priori, trascendental, es decir, el sistema de las estructuras gracias a las cuales el espíritu conoce necesariamente un objeto en general.

Este argumento de Kant, Husserl lo constituye en su punto de partida para la crítica del "psicologismo". Así, dice Kant, que, si tomásemos los principios 
de la psicología, únicamente veríamos cómo tiene lugar el pensamiento bajo las distintas condiciones subjetivas, pero sólo llegaríamos al conocimiento de leyes contingentes, no necesarias. ${ }^{1}$

Este rechazo del psicologismo, Husserl, en distintos lugares, pero sobre todo en sus Investigaciones Lógicas, lo apoya en otros argumentos, a saber:

Analizando las consecuencias del psicologismo, comprueba que esta actitud conduce al escepticismo y a todos los absurdos que lo acompañan. Si las conciencias, existentes en su diversidad, deben ser el fundamento último del conocimiento, acabamos en un relativismo que no puede sino llevarnos al escepticismo total: "Verdad más: acá de los Pirineos, error más allá", escribía Pascal. En otras palabras: no hay verdad; lo cual es inaceptable, por la razón de que el escepticismo implica la imposibilidad de cualquier tesis, inclusive la suya. "No hay verdad" es equivalente a: "Existe la verdad de que no hay verdad."

Este relativismo inadmisible se manifiesta hasta en la enunciación que da Stuart Mill del principio de identidad: "Para una misma persona, en el mismo lugar, en el mismo tiempo, es imposible pensar $A$ y no $A$." La persona, el lugar y el tiempo no tienen nada que ver aquí, piensa Husserl. Es imposible pensar $A$ y no- $A$, porque si $A$ es, no- $A$ no puede ser, y esto para cualquier persona, humana o divina.

Después de haber dilucidado y criticado las consecuencias del psicologismo, Husserl lo considera en sí mismo. La ciencia teorética que fundamente la lógica no es la psicología: el fundamento no está en mi pensamiento, sino en las cosas. ${ }^{2}$

Cuando los psicologistas expresan los principios lógicos en la forma siguiente: "Nadie puede admitir que lo mismo sea y no sea", convendría añadir: Nadie que fuera racional. Esta imposibilidad no existe sino para el que quiere juzgar correctamente, y para nadie más. No hay "necesidad" psicológica.

Además, el psicólogo que hace el inventario del contenido de un espíritu descubre allí contradicciones inadvertidas por el sujeto. "Convendría entonces -escribe Husserl- preguntarse si las contradicciones inadvertidas no serían también contradicciones, y si el principio lógico declara solamente imposibles las contradicciones advertidas."

En fin, los psicologistas creen encontrar la base de la evidencia de los principios lógicos en "la necesidad que nos constriñe a tener por cierta una conclusión; pero sigue siendo cierto que el que se aferra a un paralogismo 'siente' esta necesidad con la misma fuerza que el que razona correctamente".

La lógica posee una base teorética; pero esta base la debemos buscar en ella misma. Hay una lógica normativa porque hay una lógica teorética. Los

1 Investigaciones Lógicas, cap. III, núm. 19.

2 No ver aquí, por lo tanto, un realismo: la "cosa" de la cual se trata aquí es el objeto del pensamiento, $y$ el objeto del pensamiento no es para Husserl, como veremos, la cosa en sí, sino la estructura inmutable de las percepciones, de los juicios, etc. 
principios primeros no son normas sino porque son antes que todo principios. Cuando digo " $A$ no puede ser no- $A$ ", no enuncio una norma que habré de fundamentar por otra parte, sino la ley misma de las cosas, necesaria e intangible. Las leyes teoréticas que son la base de la lógica expresan estructuras inviolables y eternas de los seres, lo que Husserl llama esencias. ${ }^{3}$ Decir que $A$ es no-A no es solamente enunciar un absurdo en el acto de juzgar, sino una incompatibilidad entre $A$ real y no- $A$ real; lo que no quiere decir entre $A$ en sí y no- $A$ en sí. $A$, que es para Husserl la "realidad", es el objeto de pensamiento en tanto que es pensado. A partir del momento en que hay un objeto-pensado (realidad), éste es forzosamente incompatible con su contrario. Se sigue de esta precisión que, no siendo el principio de una cosa en sí, sino el de una cosa en tanto que es pensada, $o$, mejor dicho, del pensamiento de una cosa (es decir, del fenómeno, que es para Husserl la realidad), el conjunto de los principios que constituyen la lógica trascendental como base teorética de la lógica aplicada, es, a priori, como condición, no de nuestro conocimiento, sino del conocimiento en general.

En este sentido, la lógica formal que enuncia principios independientemente de cualquier contenido, como formas puras, válidas en sí, no existe. La lógica teorética es siempre trascendental, es decir, válida en función de un contenido posible. Así, cuando digo " $A$ no puede ser no- $A$ ", este principio, aunque $a$ priori, está fundamentado in re, es decir, en relación con toda realidad posible (A) y con la negación de esta realidad (no-A). En ningún caso este príncipio puede ser deducido de la experiencia, como lo quiere el positivismo: es, al contrario, la condición de esta experiencia. Husserl no entiende otra cosa cuando dice que el principio es a priori. Esto no significa que exista en sí e independientemente de toda experiencia real, sino como condición (epistemológicamente anterior) del conocimiento de una realidad que no deja, por ello, de ser su fundamento ontológico último.

Resumamos. En sus críticas del psicologismo Husserl rechaza el realismo y el dualismo de una substancia opuesta a sus propias manifestaciones. Pero se opone también al subjetivismo. "Objetiviza” el fenómeno, es decir, que le confiere una estructura extramental; o, más exactamente, fundamenta la estructura mental en una relación con el fenómeno como objeto. La conciencia no existe sino como tendida hacia algo (intencionalidad), y los principios de esta conciencia no rigen sino en función de este aliud hacia el cual la esencia misma de la conciencia consiste en tender.

Frente a la apariencia, el positivismo y el realismo tratan de "explicarla". Explicarla es abandonarla, para pasar a otra cosa que le sirva de fundamento.

3 Vemos ya anunciarse la actitud fenomenológica propia de Husserl: la esencia, que para Aristóteles y el tomismo era la naturaleza profunda de las cosas, lo que tienen en común los individuos, y que constituye el inteligible que queda en la inteligencia cuando ésta ha despojado al objeto de sus accidentes, es para Husserl la ley fundamental y necesaria de la manera como las cosas nos aparecen o son pensadas, es decir, de los fenómenos. 
La actitud explicativa supone una duda sobre la realidad de las apariencias mismas a las que la explicación tiende a substituir por otra cosa, la substancia, por ejemplo. El sabio no hace otra cosa cuando trata de reemplazar los hechos por una ley: "Desvaloriza las apariencias y valoriza las teorías hipotéticas que las fundamentan."

El positivismo introdujo tal actitud -válida para el sabio- en el campo de la filosofía. De ello resulta: 10, la inmersión en la objetividad, en lugar de la trascendencia que constituye la filosofía como tal; $2^{\circ}$, la obligación de recurrir al dualismo de los accidentes y de la substancia, cosa en sí de la cual se ignora a la vez que lo sea y qué relaciones tenga con los accidentes que la manifiestan. Debemos hacer frente al dualismo insoluble tan pronto como queramos hacer obra metafísica.

No hay un ser en sí más allá del fenómeno. El fenómeno es lo que es en sí mismo. Sartre escribirá: "La fuerza, por ejemplo, no es un conatus metafísico y de especie desconocida, que se esconda detrás de sus efectos (aceleraciones, desviaciones, etc.): es el conjunto de sus efectos. Igualmente, la corriente eléctrica no tiene un reverso secreto: no es nada sino el conjunto de las acciones físico-químicas (electrolisis, incandescencia de un filamento de carbón, desplazamiento de la aguja del galvanómetro, etc.) que la manifiestan... La apariencia remite a la serie total de las apariencias y no a una realidad escondida que habría acaparado para sí todo el ser de la existencia."

Aquí se presenta una pregunta: ¿Cómo comprender que el "en sí" de la objetividad, del fenómeno, se deje aprehender y representar? ¿Cómo, en otros términos, se puede volver subjetiva?

Lo que caracteriza el método fenomenológico es la actitud "reflexiva". Espontáneamente nuestra mirada se dirige hacia los objetos conocidos. En la fenomenología, al contrario, desviamos la mirada hacia los actos mismos de conocer para convertirlos en objetos y extraerles su sentido implícito. Ya no miro la manzana, sino mi mirada-de-la-manzana, objeto de mi conciencia reflexiva, del cual hago inventario tratando de descubrir en él, sistemáticamente, todas sus implicaciones.

Mientras que la psicología considera el contenido real de los estados de conciencia y sus condiciones prácticas, la fenomenología considera el acto de conciencia como tal, lo que este acto supone a priori y universalmente. "La fenomenología es a la psicología lo que las matemáticas puras son a la física."

3. Se trata de saber ahora si esta intuición de las relaciones fundamentales, como las llama Husserl, halla al ser y al inteligible.

Sí, piensa Husserl; porque, al contrario de lo que creía Kant, la intuición intelectual existe: captamos inmediatamente, de una sola mirada, y no de manera discursiva, realidades ideales. El cogito es la primera de estas intuiciones 
y garantiza todas las demás. Veo este rojo; tengo de él una aprehensión directa (intuición); pero es preciso que tenga también la intuición de la "rojez", sin la cual "veo este rojo" no tendría, en rigor, ningún sentido. La intuición, para Husserl al igual que para Bergson, permite a la conciencia lograr el ser "en los datos inmediatos de la conciencia". Con los dos grandes iniciadores del pensamiento moderno, Descartes se restaura: el cogito es el "lugar filosófico" privilegiado, el punto de encuentro único del ser y del conocer.

Es evidente que una posición de esta índole obliga a Husserl a volver a una concepción cartesiana de la verdad. La definición realista de la verdad ("adaequatio rei et intellectus"; la concordancia de la cosa y el pensamiento) no enuncia sino un círculo vicioso. Para verificar si la "cosa" coincide con mi pensamiento, debo saber primero lo que es en sí esta cosa, es decir, estar ya asegurado de la posesión de la verdad, lo que es precisamente el problema. Es un círculo vicioso que se explica por el hecho de que el pensamiento y la verificación son ambos fenómenos de conciencia.

No hay, pues, otra actitud posible que la de buscar en el seno mismo del pensamiento el criterio de la realidad y de la verdad. Pero, entonces, ¿̇no corremos el riesgo de recaer en este subjetivismo relativista que Husserl combatía en los psicologistas? ¿Hacemos, acaso, otra cosa que volver al escepticismo de Protágoras? ¿No se convierte el hombre en "la medida de todas las cosas"? No, no caemos, de esta manera, piensa Husserl, ni en el subjetivismo ni en el relativismo.

No hay subjetivismo por la buena razón de que los datos de conciencia que la fenomenología considera son objetos distintos en sí de la conciencia, puesto que ésta puede tomar para con ellos la distancia que caracteriza la actitud reflexiva. No hay tampoco relativismo, puesto que, al contrario, son las estructuras ideales a priori las que fundamentan la necesidad de la universalidad. En Husserl, como en Descartes, el cogito se constituye al negar toda realidad contingente, inclusive la del yo al cual está vinculado. Su dimensión misma es la universalidad.

4. El cogito. La necesidad apodíctica de la lógica no está fundamentada, como hemos visto, en la psicología: contiene en sí misma su necesidad y su certidumbre. ¿Pero en qué fundamentar, en último análisis, esta certidumbre misma? Después de Descartes, y como él, Husserl experimenta la exigencia de una certidumbre apodíctica.

Al contrario de Hume y Kant, le parece que la experiencia no presenta este carácter de evidencia que deben revestir las verdades que sólo admite un filósofo crítico. El ser de las cosas es puramente fenoménico, contingente, subjetivo. El ser parece recibir de la conciencia sus estructuras, hasta el punto que pensar una realidad fuera de la conciencia es pensar en el vacío.

Si el punto de partida del filósofo debe ser una evidencia apodíctica, 
debémos confesar que la existencia del mundo exterior no puede de ninguna manera ser este punto de partida. Es posible la no-existencia del mundo. Los fenómenos que componen mi experiencia del mundo exterior pueden perder su validez. El mundo no me es dado sino como "lo que me aparece"; no es evidente, ni en sus partes ni en su totalidad. No me presenta ninguno de los caracteres que harían de él una evidencia apodíctica y necesaria. Puede ser "puesto fuera de juego, puesto entre paréntesis", dice Husserl.

De esto se sigue que si la filosofía es una tentativa de búsqueda de un fundamento absoluto, ha de buscarlo en otra parte.

Si los fenómenos son "desvalorizables", presuponen siempre la existencia del cogito. Puedo poner el universo entero entre paréntesis, pero permanece aquello con que lo pongo entre paréntesis. Puedo dudar de todo, pero queda la duda como acto de un cogito. Este cogito, ergo sum, es la primera evidencia para Husserl, como lo era para Descartes, cuya actitud fundamental, hasta ahora, el filósofo alemán no hace sino tomar por su cuenta: búsqueda de una certidumbre; duda para con todo lo que no presenta esta certidumbre en una evidencia apodíctica; duda que se extiende necesariamente a todo, menos al cogito mismo.

Luego, el camino seguido por Husserl lo aleja de Descartes. La "falla" cartesiana consiste, según Husserl, en haber hecho del ego como "substancia" pensante el punto de partida de deducciones, según el principio de causalidad. En lugar de deducciones, Husserl quiere proceder por evidencias apodícticas implicadas en el primer descubrimiento cierto (el del cogito).

Es, pues, un inventario de lo que implica el cogito lo que se propone Husserl. La captación misma de este cogito fuera del conocimiento inmediato de un objeto, en la actitud reflexiva, ha conducido a Husserl a distinguir la experiencia sensible de la experiencia trascendental.

En la experiencia sensible se me manifiesta un objeto (el rojo de esta pared, por ejemplo). Pero puedo tomar una actitud reflexiva, colocarme a distancia de esta totalidad: mi-experiencia-de-este-rojo. Trasciendo así la experiencia inmediata, mi objeto ya no es este rojo sobre esta pared; mi mirada en-este-rojo es la que se vuelve, a su vez, objeto de una experiencia ya trascendental.

El cogito es trascendental en el sentido que su fin no será volver a juntarse con el mundo de los objetos, como en Descartes, sino inventariar su propio dinamismo.

La singularidad de la fenomenología, en su oposición a las disciplinas objetivas, consiste en considerar siempre la experiencia trascendental. Hasta ahora las ciencias de la subjetividad (como la psicología) habían considerado la subjetividad "realizada objetivamente" en el mundo. Se trata ahora, por el contrario, de investigar el ego en tanto que es sujeto de experiencia trascendental, excluyendo toda "objetivación" psicofísica (alma-cuerpo). 
De esto se sigue que la actitud fenomenológica, la actitud reflexiva, la experiencia trascendental, son tres términos que se evocan recíprocamente. Describir el cogito trascendental (es decir, el de Descartes) en su acto de cogitans, para explicitar su contenido trascendental (lo que este acto significa para el cogito): tal es la fenomenología trascendental, la cual se hace posible por la actitud reflexiva. El contenido objetivo del cogito (es decir, lo que "llena" la conciencia de "cosas": pereepciones, imaginaciones, etc.) constituye el objeto de la psicología y, como tal, no interesa al fenomenólogo.

En efecto, la significación apodíctica del cogito, tal como la desprendió Descartes del mundo de la objetividad para trascender a este mundo, no se reduce a la existencia del ego; incluye una estructura que Husserl llama la "concreción", accesibilidad a una experiencia interna posible. ${ }^{4}$ Este "pensamiento" que trasciende sus objetos no es una idea general, obtenida por abstracción, como se obtienen los caracteres de la especie, dejando de lado las atribuciones individuales. No se ha hecho abstracción de los pensamientos individuales para hallar el pensamiento en general. Solamente se ha comprobado que el cogito sobrepasa todo contenido, se establece como certidumbre independientemente de este contenido. Pero este cogito trascendental y universal no es, por ello, menos concreto, es decir, experimentable, intuíble concretamente y no deductible.

El argumento realista contra Descartes (no se puede deducir una existencia de una idea; ninguna idea implica su existencia) cae ante la precisión de Husserl: el pensamiento del cogito trascendental no es una idea general deducida, abstracta; ${ }^{5}$ es la captación de lo universal en la concreción misma, el pensamiento en mis pensamientos, la cogitatio en el cogito que, por ser reflexivo y trascendental, no deja, por ello, de ser concreto: el cogito de $m i$ experiencia trascendental.

Ahora bien: el primer aspecto que hallo con evidencia, cuando trato de hacer explícito lo que "contiene" mi experiencia trascendental, es esta característica que posee el cogito y que lo constituye, de tender hacia una realidad fuera de sí. El primer carácter apodíctico del cogito, tal como me lo revela la descripción fenomenológica de mi experiencia trascendental, es la intencio-

4 Es útil recordar aquí lo que Husserl entiende por evidencia apodíctica, aunque hayamos utilizado ya este concepto para defender a Descartes de los argumentos del realismo. Hay evidencia inmediata cuando una verdad parece fundada in re y aceptada por la conciencia no reflexiva; en una palabra: cuando no se duda. La evidencia apodíctica es fundada in ratione: no se puede dudar de ella. El mundo exterior frente a mí es una evidencia inmediata: tan pronto como un sujeto conoce, su acto mismo implica la evidencia de la exiscia de lo que conoce. Sin embargo, entre estos dos términos -el sujeto y el mundo objetivola razón puede introducir una duda: no es una evidencia apodíctica. Al contrario, entre el "yo" pensante y su existencia ninguna duda puede ser introducida, puesto que no hay dos términos, sino uno solo, cuyo acto mismo implica la existencia.

5 Hemos notado al estudiar a Descartes que su tendencia era también descubrir implicaciones; su única deducción a partir del principio de causalidad es la del mundo exterior como causa de mis sensaciones, garantizada por la veracidad divina. 
nalidad. Husserl llama así precisamente a esta particularidad de la conciencia de ser "conciencia de". El cogito es correlativo a un cogitatum. La conciencia está tendida hacia un objeto, hacia el objeto en general, cualquiera que sea. A la conciencia, en tanto que "desea" el objeto sin el cual no es nada, Husserl la llama conciencia intencional. El objeto en general, en tanto que es "deseado" por la conciencia como su correlativo, recibe el nombre de "objeto intencional". ${ }^{\circ}$

Los caracteres que pertenecen a la conciencia intencional los llama Husserl noéticos; los que convienen al objeto intencional reciben el nombre de "noemáticos". En otros términos, son neóticos los modos de percibir (percepción sensible, memoria, imaginación, etc.). Son noemáticos los modos de ser percibidos (como presente, posible, real, etc.). Los modos noemáticos son correlativos a los néticos, como el objeto intencional es correlativo a la conciencia intencional. A la percepción (como modo noético, es decir, como modo de aprehensión de la conciencia) corresponde la presencia (como noemático, es decir, como de ser aprehendido el objeto), etc.

El campo ilimitado de la vida pura de la conciencia, es decir, el cogito en su intencionalidad total, implica, pues, forzosamente, el mundo-fenómeno que es el correlato noemático de la conciencia.

Las correlaciones noéticas-noemáticas son concretas e individuales, como ya hemos señalado. La fenomenología quiere hallar la individualidad y la "concreción" de sus estados. Para que su descripción sea precisa, el fenomenólogo no describirá "el acto del yo cuando mira una cosa" (esto sería recaer en la generalización, la abstracción y, al contrario de lo que Aristóteles creía, perder posibilidades de lograr lo universal), sino "mi mirada $\rightarrow$ la casa"; indicando la flecha que esta mirada se considera en su intencionalidad, sin la cual se desvanece. Estas correlaciones presentarán ciertas formas de unidad que será preciso revelar, tratando así de descubrir en ello la unidad del "yo" concreto mismo.

Nunca insistiremos demasiado, al tratar de expresar el pensamiento de Husserl, en el hecho de que el "yo concreto" se opone al "yo abstracto", a la idea general del yo, y no al "yo" considerado en su significado más universal. No se trata de abstraer, a partir de los actos del yo, estructuras objetivas teóricas, sino de considerar este yo en su situación intencional característica. Hay "concreción" en el sentido de que el yo concreto es el sujeto reflexivo de la investigación. Hay universalidad en el sentido de que no considero tal modo de representación de mi yo, sino todos los modos posibles.

La duración interna de la conciencia no es una serie de cogitationes vincu-

6 Utilizamos los términos: “deseado", "desea", por analogía con nuestra conciencia afectiva. Hay, evidentemente, que vaciar aquí estos términos de la afectividad que connotan, para no conservar sino el sentido de llamado, de tensión, de vacío y de saturación. Santo Tomás no procede de otra manera cuando define el Bien trascendental: "el Ser en tanto que es deseable" (appetibile). El físico usó la misma particularidad evocadora del lenguaje cuando decía, por ejemplo, que la naturaleza "tiene horror" al vacío. 
ladas entre sí, sino una síntesis. Es una conciencia una en la y por la que se constituye la unidad de una entidad intencional: "el mismo cubo -el mismo para la conciencia- puede estar presente en la conciencia (en el mismo tiempo, o sucesivamente) en modos de conciencia separados y muy diferentes; por ejemplo, percepción, recuerdo, anticipación, juicio de valor, etc.".

Sólo una síntesis (y no una asociación) puede realizar la conciencia de una unidad en la unidad de una conciencia que me hace posible todo conocimiento de la identidad.

Esta síntesis no se limita a esto: no vincula solamente estados individuales, sino todos los estados posibles de la conciencia. La conciencia considerada como síntesis de todos los estados posibles: esto es lo que Husserl llama el cogito universal.

La forma de esta síntesis, como ya lo había visto Kant, es la conciencia inmanente del tiempo. Por esto el cogito de que se trata debe ser a la vez universal y concreto, es decir, considerado en su dimensión concreta: el tiempo.

Se trata de buscar precisamente el carácter incondicionado, universal, de lo concreto mismo; lo que Husserl llama eidos. La fenomenología "eidética" tratará de descubrir el sentido universal e incondicionado, del cual el condicionado es "signo". Este acto de mi "yo" significa, es decir, remite a. . . No remite a una substancia, a una esencia general, colocada detrás de este acto, y a la que tendríamos que abstraer de él. Remite a la totalidad de los actos posibles, es decir, al campo ilimitado de la conciencia, el cogito, al cual revela en cierta forma. La significación de este acto concreto, que no se puede captar sino en su sola "concreción", tal es el eidos que busca el fenomenólogo.

El análisis fenomenológico revela que este mismo ego, sujeto del cogito, se halla como "un yo que vive esto o aquello". El cogito, en efecto, es la causa $\mathrm{d} \epsilon$ actos que constituyen un ser, un yo cuyas estructuras son articuladas por la corriente de la conciencia. Un acto pasado del cogito permanece presente en cierta forma, y esto no por el solo recuerdo de este acto. Un poco a la manera del existencialista, para quien la existencia precede a la esencia, Husserl no concibe el yo como una substancia dada, hecha, que luego actuaría. Contra lo afirmado por Aristóteles, no piensa que tengamos primero una esencia general, la de hombre, y luego esta esencia "piense", engendrando así el cogito. Todo pasa, por el contrario, como si la conciencia se constituyera por sus propios actos, como el hecho de un río y el río mismo se constituyen por su propia corriente. ${ }^{7}$ ¿Cómo no evocar estos versos de Valéry?:

$T u$ n'as pas perdu ces heures

Si légère tu demeures

Après ces beaux abandons;

7 Atisbamos el tipo de titica y de Estética que se desprende de esta concepción. Los actos valen no tanto en sí como en la medida en que nos constituyen, proporcionándonos nuestro "rostro". Un cierto narcisismo está muy cerca. 
Pareille d celui qui pense

Et dont l'ame se dépense

A $s^{\prime}$ accroitre de ses dons! 8

Este "yo", engendrado así, como en una magnífica y angustiosa autocreación, Husserl no puede decir que sea una substancia sin despertar todos los dualismos insolubles. Su autoconstitución misma es incompatible con el concepto clásico de substancia: el yo se constituye a sí mismo como sujeto idéntico con sus apropiaciones permanentes, es decir, con lo que conserva de los actos o de la negación de sus actos. Es, según Husserl, el "polo" de sus actos, y a esta palabra le da un sentido muy análogo al que se le da en electricidad. A este "polo" Husserl lo llama una mónada y prefiere utilizar la terminología de Leibniz para escapar a la "substancia pensante" de Descartes, quien no totalmente liberado de la escolástica, se expresa como si hubiera ontológicamente una substancia anterior a sus actos. Esta mónada, al pasar de la fenomenología a la psicología, se vuelve el "alma" tomada como objeto.

Pero la característica fundamental del cogito, del ego trascendental, frente a este yo, es la posibilidad de desvalorizarlo, de ponerlo entre paréntesis, como a los otros fenómenos que constituyen el mundo. El cogito es esencialmente trascendencia, y en tanto que intencionalidad pura, trasciende a este yo mismo que engendra por sus actos. Es lo que Sartre entenderá cuando defina la conciencia como libertad. Entre el cogito y el yo, hay "juego" (en el sentido en que se dice que hay juego entre las ruedas de un engranaje no exactamente adaptadas). El cogito es libertad por la buena razón de que se constituye como trascendental y se arranca a la inmanencia del yo que engendra al rehusarse.

Paul Valéry, antes que Sartre, había notado estos dos caracteres correlativos de la conciencia, contenidos implícitamente en la noción husserliana de intencionalidad, pero que el filósofo alemán no ha desprendido claramente: el rehusarse y la presencia. La conciencia se constituye, nos dice Valéry, "rehusándose indefinidamente a ser cualquier cosa"; la conciencia debe negar de sí misma todo, inclusive este "yo" que ella engendra, para constituirse como presencia pura ante este mismo "yo" que ve, juzga, acepta o rechaza. Un rehusar como el de "la mer toujours recomencée", puesto que deberá luego ver su mirada, juzgar su juicio, aceptar o rehusar su aceptación o su rechazo mismo.

L'âme exposée aux torches du solstice, Je te soutiens, admirable justice De la lumière aux armes sans pitié. Je te rends pure d ta place première: Regarde toi!...

8 Paul Valéry, Charmes, poema "Palme". 
Este arrancarse constituye la conciencia como presencia. No es presencia ante todo sino porque no se identifica con nada. Presencia ante la durée de las cosas y de los estados de conciencia, se desprende de ella para constituirse a sí misma y dar sentido a esta duración.

\author{
Midi là haut, midi sans mouvement, \\ En soi se pense et convient à soi-même... \\ Tête complète et parfait ảiadème, \\ Je suis en toi le secret changement.
}

5. El mundo exterior. El hecho de no haber visto todas las implicaciones de la intencionalidad pone a Husserl en apuros cuando se trata de la existencia del mundo exterior, en tanto que es heterogéneo a la conciencia. Ciertos pasajes parecen inducirnos a concluir que un mundo tal existe; otros, al contrario, implicarían un idealismo radical. La evolución de Husserl lo conduce hacia posiciones más y más cercanas a las del kantismo, que al principio rechazaba. Expondremos primero el realismo husserliano, es decir, lo que en él es explícita o implícitamente afirmación del mundo exterior, cuyo ser no se reduce a un simple percipi. Luego veremos a Husserl orientarse, en cierta forma a pesar suyo, hacia el idealismo. En fin, trataremos de dilucidar el porqué de este conflicto, y cómo se puede escapar de él, colocándonos en el plano sartriano de un análisis, no del conocimiento, sino del cognoscente.

El análisis mismo que Husserl efectúa de las estructuras del cogito implica, según parece primeramente, la existencia de un mundo exterior, en tanto que es heterogéneo a la conciencia. No hay ningún ser de la conciencia fuera de esta obligación de ser intuición inmediata del "otro", en tanto que otro (intencionalidad). El cogito goza de una doble trascendencia. Es trascendente en tanto que, dotado de poder reflexivo, puede constituirse como presencia ante sus propios actos, su propio dinamismo. Pero es también trascendente en el sentido de que "el ser del cogito" se coloca frente al ser del mundo.

Al hallar la conciencia como sujeto, Husserl la descubre al mismo tiempo como correlativa. Siendo ella sujeto, se constituye negando de sí misma una objetividad que, por lo tanto, ella supone. Hay, pues, a la vez objetividad, sin la cual no existiría una conciencia como sujeto, y heterogeneidad del objeto, sin la cual la conciencia no necesitaría desprenderse del objeto para constituirse como conciencia. Husserl llega hasta precisar que la conciencia contiene un "núcleo hylético" para permitir el conocimiento de la materia exterior a ella. Los elementos hyléticos -materiales- son los datos reales inmediatos de la conciencia. La actividad intencional de la conciencia dota al "fenómeno hylético" de un sentido trascendental.

¿No es acaso la definición misma de la intencionalidad, como carácter esencial de la conciencia, de ser ad aliud, tensión hacia un objeto pre-supuesto? Todo el ser de la conciencia se agota en el hecho de entrar en relación con 
algo que no sea ella misma. De ahí, como hemos visto, esta doble serie de modos -noéticos y noemáticos- que, por correlativos que sean, no dejan de afectar, por lo tanto, a dos realidades distintas.

Además, Husserl señala que una de las primeras comprobaciones de la investigación fenomenológica es que la percepción nos aparece como una doble duración. Al percibir un cubo se desprenden dos duraciones, la (interna) de la percepción del cubo, y la (objetiva) del cubo mismo. Además Husserl, estudiando la inter-subjetividad, admite la existencia de otras conciencias, de otros "yo" frente a los cuales se presenta un mundo común. Hay "algo" frente a nosotros. La exterioridad del "yo" de los demás encamina necesariamente a la exterioridad del mundo. "Este mundo, esta Naturaleza, es necesario que exista, si es cierto que llevo en mí estructuras que implican la existencia de otras mónadas."

6. Todo hasta aquí nos parece llevar a la conclusión de que hay una realidad de los fenómenos exteriores y heterogéneos a la conciencia. Esta conclusión parece menos firme en otros pasajes de nuestro autor. Ya su posición metodológica constituye una amenaza. El filósofo deja de considerar la relación "pensamiento-cosa" y se enfrenta a la totalidad "sujeto-predicado"; y esto, como hemos señalado, en el acto del sujeto. Si el método se limita deliberadamente a inventariar el cogito, parece difícil hallar en él algo que sea heterogéneo a él mismo. Grande es el riesgo de no encontrar aquí sino percipere o percipi, lo que nos lleva ineludiblemente al idealismo de Berkeley.

Creímos estar a salvo del idealismo radical por la intencionalidad de la conciencia. Pero difícilmente se entiende cómo esta intencionalidad podría dirigirse hacia algo heterogéneo a la conciencia. ¿Cómo concebir una interacción entre dos entidades que no participan de la misma naturaleza? Por esto Husserl precisa que la conciencia intencional no se dirige hacia "algo fuera de nosotros", sino a una "objetividad ideal": el fenomenólogo considera "el rojo de mi sensación", y no "este rojo, allá en la pared". También es cierto que Husserl advierte que esta objetividad ideal no es algo contenido en la conciencia, como para el idealista. Pero esta precisión no logra salvar a Husserl del idealismo radical. ‘¿De qué naturaleza, en efecto, es esta objetividad? Si es heterogénea a la conciencia, debemos admitir que es "algo fuera", lo cual, no sin razón, repugna a Husserl admitir; si es de naturaleza psíquica, está, pues, contenida en la conciencia como un percipi, y se acabó a la vez con el mundo exterior y con la conciencia como intencionalidad.

Para Husserl, "el ser real" (Wierklichsein) del mundo es inseparable de la "verdad". Se trata de la evidencia para una conciencia de esta realidad. En otros términos, si el cogito, como conciencia intencional, es correlativo de un cogitatum -aquí el mundo-, este mundo, recíprocamente, no puede ser considerado sino como correlativo del cogito. Además, la verdad tiene su funda- 
mento trascendental en el cogito. La existencia del mundo es evidente, pero sólo en el sentido de que este mundo es el correlato de la conciencia externa, la cual sigue siendo el criterio último. "El mundo -escribe Husserl- es una idea infinita correlativa a la idea de una síntesis completa de las experiencias posibles." No se puede otorgar al mundo menos realidad.

¿Pero entonces el ego engendra al mundo? En el sentido de "génesis activa", en la cual el "yo" produce sus actos propios, voluntarios o racionales, no, contesta Husserl. Pero, en tanto" que "presencia ante...", engendro pasivamente todo un sistema de vinculaciones que, de un "dato bruto", hará "la cosa para mí". Es de temerse que con este dato bruto ocurra lo que ocurrió con el "algo" misterioso que, en la percepción kantiana, venía a alojarse en los cuadros a priori, espacio y tiempo. Cae bajo los golpes de la implacable lógica berkeliana. ¿Es conocido? Luego es de orden psíquico, es un hecho de conciencia. ¿No es conocido? ¿Cómo entonces una filosofía que quiere ser apodíctica puede afirmarlo?

La existencia de la cosa material no percibida no es otra cosa que la posibilidad que tiene de ser percibida, concede Husserl. Su realidad es su "perceptibilidad". Esta noción evoca la materia de Aristóteles, que no es, ni es tal, sino en y por la forma. Pero aquí la forma viene de la conciencia; en la medida en la que la conciencia hace pasar al acto esta pura posibilidad, la engendra verdaderamente, le confiere su naturaleza, y ésta es, pues, necesariamente psíquica.

Husserl no parece conceder a Berkeley todo lo que éste exige, cuando escribe en las Meditaciones: "La conciencia, en su conciencia del mundo, así como en su actividad científica, no sale de sí misma... Pero ¿cómo puede todo este juego, desarrollándose en la inmanencia de mi conciencia, adquirir una significación objetiva? La evidencia (la clara et distincta perceptio) ¿cómo puede tener otro carácter que el de mi conciencia en mí? ... Querer hallar un universo del ser verdadero como algo que se encuentra fuera del universo de la conciencia, es absurdo." Debemos entendernos: es cierto que no podemos hallar este ser, es decir, tomar conciencia de él, pretendiendo mantenerlo fuera de la conciencia como intencionalidad. Pero esto no impide hallarlo fuera de la conciencia como ser. Que sea captado en el "cono de luz" de la conciencia real o posible, y solamente en este cono, lo admitimos. Queda por establecer, lo que Husserl no parece haber hecho, que el ser de este mundo no es este cono de luz ... o bien admitir que sí lo es; pero entonces se acabó la conciencia como intencionalidad, es decir, como esencialmente orientada ad aliud.

7. Si Husserl ha vuelto a caer en los dualismos insolubles (los del sujeto cognoscente y el objeto heterogéneo) después de haber superado los de la apariencia y la substancia más allá de sus apariencias, es, según Sartre, por- 
que finalmente ha desertado del terreno que había, sin embargo, establecido tan sólidamente; el de la fenomenología del sujeto cognoscente, para colocarse en el del clásico problema crítico: ¿Cómo admitir a la vez la existencia y la comunicación de dos realidades heterógenas, la de la conciencia y la del mundo exterior? Así fué llevado Husserl a transferir a la conciencia la totalidad del ser, a riesgo de ver reabsorberse en ella toda la realidad de la cual es conciencia.

Había sido necesario hacer inventario de esta totalidad que es "mi conciencia del mundo", en lugar de establecerse en los altos lugares de un cogito reflexivo y exponerse a no poder regresar.

Así aparece que la trascendencia del cogito es correlativa de la trascendencia del mundo. El fenómeno no necesita ninguna esencia "detrás de él", pero exige la transfenomenidad de su ser mismo. Hay el objeto y el ser del objeto, no en el sentido de que el objeto "posee" el ser, participa del ser, de un ser escondido tras de él: es, nada más. Pero el ser del fenómeno no se deja reducir a un fenómeno de ser, lo cual no significa otra cosa sino que el ser del fenómeno no existe únicamente en tanto que es percibido, no se reduce al percipi: desborda el conocimiento mismo que se tomó de él. Que el fenómeno sea lo que aparece, que lo que aparece sea, no significa que su ser sea aparecer.

En el idealismo, la conciencia misma corre grandes peligros. Es para sí misma una apariencia (tener conciencia de este rojo es poder considerar mi conciencia de este rojo). Es este poder mismo de la conciencia de aparecer ante sí misma, de constituirse como conciencia de sí misma, lo que la caracteriza. "Si mi conciencia no fuera conciencia de ser conciencia de mesa, sería, pues, conciencia de esta mesa sin tener conciencia de serlo, o en otras palabras, una conciencia que se ignorara a sí misma, una conciencia inconsciente, lo cual es absurdo."

Sartre nota juiciosamente que si se reduce el ser al conocimiento que se toma de él, será preciso asegurarse primero del ser del conocimiento; a riesgo de ver como la relación percepción-percibido se desvanece. ¿Pero qué fundamentará el ser del conocimiento? No puede ser el conocimiento mismo (sería un círculo vicioso). Este ser es, pues, "transfenoménico" y no podrá revelarse sino en experiencias existenciales. Debemos entonces abandonar la primacía del conocimiento, si queremos fundamentar este conocimiento mismo. "Criticarlo" es infecundo. Es preciso inventariarlo fenomenológicamente, o más exactamente, explicitar el ser del sujeto cognoscente.

¿Cuáles son los datos de este inventario? La mesa no está en mi conciencia, sino "en el espacio, al lado de la ventana". La mesa se reduce tan poço al percipi, que es al contrario un "centro de opacidad" para la conciencia. Cada cosa que la conciencia "arranca" de la mesa la remite a otros datos que la mesa parece querer "esconder". Esto, precisa Sartre, no es suficiente para afirmar 
que esta mesa existe en sí, pero sí que "existe para mí", implicando la heterogeneidad para mí de esta mesa y de mí mismo como conciencia.

Debemos, pues, otorgar un ser a esta mesa. Este ser, nos dice el idealismo, no es otra cosa que el de un percipi. Sabemos en todo caso que este ser del percipi no se reduce al del percipiens. Este percipi es pasivo. Pero, para ser pasivo, por lo menos es preciso ser. La pasividad no puede afectar a la existencia misma del ser pasivo, sin que todo caiga en la nada. La pasividad es forzosamente "un fenómeno doblemente relativo: relativo a la actividad del que actúa y a la existencia del que la padece. Es imposible que el percipere afecte al perceptum en su existencia, ya que para ser afectado, sería necesario que el perceptum fuera ya dado en cierta forma, que existiera, pues, antes de haber recibido el ser".

Hay finalmente dos posibilidades. O bien la conciencia es constitutiva del ser de su objeto, o bien es relación a un ser trascendente.

El error de Husserl parece provenír de que hace de la conciencia esencialmente "lo que es". La opone a su objeto, el cual se convierte, correlativamente, en "lo que no es". Esta actitud queda rebatida por un análisis fenomenológico de las estructuras del cognoscente. Si la conciencia es esencialmente "lo que no es", su dimensión fundamental es la negación. Hemos visto precisamente que se constituye por la "negativa indefinida a ser cualquier cosa", y negando de sí misma aquello hacia lo cual, por otra parte, ella tiende: todo lo que es. "A veces pienso, a veces soy", escribe Valéry, parafraseando a Descartes.

"Conocer es no ser." Mi mano puesta sobre esta mesa no conoce la mesa sino porque no es ella. Le está presente, no le es. A partir del momento en que le fuera idéntica, ya no habría conocimiento. Tan íntima como podamos concebir la presencia de una conciencia ante un objeto, hay siempre entre esta conciencia y este objeto una "nada" que les impide coincidir. No conozco verdaderamente sino aquello con lo que jamás podré identificarme: lo que no soy.

No sirve objetar que me conozca a mí mismo. Lo que puedo conocer de mí (carácter, tendencias, ideas, sentimientos, etc.) es un "yo-objeto", tal como l: revelan mis actos pasados, un "yo" muerto a la subjetividad. Mi espontaneidad, mi subjetividad, es decir, mi presente, totalmente ocupado en investigar este "yo-objeto", es mi mirada a este "yo", mi conciencia de este "yo". Esta conciencia es esencialmente presencia ante... mí. En su acto mismo de mirar, se aleja de este "mí", no lo es. Fuera de esta presencia, ella es rigurosamente nada.

El análisis fenomenológico del cognoscente -y no del conocimiento-, al cual Husserl fué infiel, revela que la conciencia se pone como un vacío frente a un ser que es lo que a ella le falta para ser ... y para dejar de existir como. conciencia. Tal es el sentido profundo del descubrimiento husserliano de la 
intençionalidad, cuyo alcance Husserl mismo no sospechó. La conciencia tiende hacia el ser, "aspira" al ser, porque no lo es; o más precisamente, para volver a tomar la expresión de Sartre, porque "es en el modo de no ser".

$\because$ Desde luego, la existencia del mundo exterior se revela en una prueba ontológica, como lo había visto ya Descartes. La diferencia, sin embargo, con la argumentación cartesiana es doble. Primero, no se trata de partir de una substancia (el pensamiento) para llegar a otra substancia (la extensión) mediante la existencia de un ser perfecto que garantizaría el paso. Segundo, la prueba ontológica ya no se deriva de un cogito reflexivo (que, una vez aislado de su acto, permanece así definitivamente), sino del ser mismo del cognoscénte, tal como presenta sus estructuras ante el análisis fenomenológico. Esta prueba ontológica, que consiste en ver el ser del mundo exterior fenomenológicamente implicado en las estructuras inmediatas del cognoscente en su acto concreto, puede reducirse al esquema siguiente:

La conciencia se halla, en su acto; como "falta de...", como "lo que no es"; este ser del cual carece es el objeto conocido en tanto que objeto intencional; este ser está, pues, fuera de la conciencia.

Así la fenomenología, que con Husserl no logra conciliar estos dos seres (conciencia y objeto) y reabsorbe uno en el otro, encuentra su acabamiento cuando el análisis del cognoscente revela un existente cuya naturaleza entera consiste en carecer de ser, en ser vacío, llamado al ser, presencia ante el ser; y bajo pena de caer en la pura nada, este ser se supone ajeno al que, por esencia, no es:

Abstraer es considerar separadamente lo que no existe precisamente sino con la condición de no estar separado. La conciencia es, en este sentido, una abstracción. Husserl decidió considerar a la conciencia en su "concreción", presintiendo que sólo así podría describirla fenomenológicamente. Su fracaso proviene finalmente de que, siendo la conciencia en sí un abstracto, no puede considerársela concretamente. Lo concreto no es la conciencia sino, como lo vió Heidegger, "mi-ser-en-el-mundo". De él solamente debe emanar el análisis fenomenológico, y sobre él debe fundarse este análisis. Pero aceptar esta totalidad: "cognoscente-de-un-conocido", ¿no es acaso evadir el problema crítico?

8. Parece que hayamos cerrado el círculo. Hemos partido de un realismo que rehusaba criticar el conocimiento, por cuanto la razón debía justificarse a sí misma, lo cual era imposible; finalizamos en un existencialismo que declara que el conocimiento no puede constituir el fundamento del ser que conoce. Los ecos metafísicos que despierta el existencialismo están por cierto muy lejos de concordar con las resonancias realistas, y esto casi en todos sus puntos. Lo que nos interesa aquí señalar es esta común "inmersión" en un mundo admitido como un hecho. Evidencia, decían los peripatéticos; prueba 
ontológica, dice Sartre. Hemos visto lo que se podía pensar de la evidencia del "sentido común", y que hay mucha distancia entre ésta y la evidencia apodíctica que, con Descartes y Husserl, el hombre no puede por menos de exigir. Esta "evidencia" es un postulado, o tal vez una simple opción. La prueba ontológica sartriana no parece tampoco satisfacer totalmente nuestras exigencias. ¿Nos ofrece la conclusión algo que no contengan las premisas? Es evidente, $l^{o}$, que si creo en los datos de mi experiencia. (análisis fenomenológico de lo existente) , y $2^{\circ}$, que si esta experiencia me revela a mí mismo como una presencia ante un mundo que existe fuera de mí, este mundo es necesariamente. Pero creer en mi experiencia, admitir las estructuras que revela la explicitación de lo existente, es también una opción o un postulado. Es posible que estemos condenados a lo primero, pero esto no lo convierte sin más en una certidumbre apodíctica. En otros términos, es posible -y hasta probableque Sartre tenga razón al preferir una explicitación del ser del cognoscente, en tanto que existente; pero no es menos cierto que no puede encontrar ahí el fundamento del conocimiento. Aceptamos su crítica del substancialismo aristotélico y cartesiano, sus notas penetrantes sobre el callejón sin salida en que Husserl ha seguido a Descartes, al colocar su búsqueda en el nivel del cogito reflexivo. Admitimos su notable crítica del idealismo; experimentamos, con Valéry y con él, nuestra existencia de seres conscientes como un vacío, una "falta de", una presencia ante un ser... que está ausente de nosotros. Pero no podemos conceder que nuestra exigencia de certidumbre quede satisfecha de este modo. El conocimiento está descrito; sus implicaciones están manifiestas. Pero no está fundamentado. No lo está, porque no lo puede estar in ratione. El drama viene de que es precisamente esta fundamentación in ratione lo que exigimos. En fin, dhay acaso otra actitud que la duda definitiva, que el cogito reflexivo, el cual, renunciando a juntarse con el ser en una evidencia apodíctica, goce estéticamente de su acto propio, como lo hace Valéry; o bien la opción, la elección, el "engagement", que nos revela a nosotros mismos, si creemos, con Gabriel Marcel, en una persona que comunica, no en la razón abstracta, sino en su más íntima existencia, con el absoluto en que toda certidumbre descansa?

\section{Churustian Brunet}

Universidad de Nuevo León, Monterrey, N. L., México 